\title{
Excessive TV viewing and cardiovascular disease risk factors in adolescents. The AVENA cross-sectional study
}

\author{
David Martinez-Gomez1,2, J Pablo Rey-López³, Palma Chillón44, Sonia Gómez-Martínez1', Germán Vicente-Rodríguez³, \\ Miguel Martín-Matillas ${ }^{4}$, Miguel Garcia-Fuentes ${ }^{5}$, Manuel Delgado4, Luis A Moreno 3 , Oscar L Veiga², \\ Joey C Eisenmann', Ascension Marcos*1 and AVENA Study Group
}

\begin{abstract}
Background: Excessive television (TV) viewing might play an important role in the development of cardiovascular disease (CVD). The aim of this study was to examine the independent associations between TV viewing and CVD risk factors in adolescents.

Methods: A sample of 425 adolescents, aged 13- to 18.5-year-old, was included in this study. Body mass index (BMI), waist circumference (WC), glucose, total cholesterol, triglycerides, HDL-cholesterol, LDL-cholesterol, apolipoprotein (apo) A-1, apo B-100, and lipoprotein(a) levels were determined. A composite CVD risk score was computed based on age-, sex-, sexual maturation- and race-standardized triglycerides, HDL-cholesterol, LDL-cholesterol and glucose. TV viewing was self-reported.

Results: Two hundred and twenty-five adolescents (53\%) who spent $>3 \mathrm{hrs} /$ day watching TV were considered as the "high TV viewing" group. Ninety-nine adolescents (23\%) from the total sample were classified as overweight according to International age- and sex-specific BMI values. The high TV viewing group had significantly less favorable values of HDL-cholesterol, glucose, apo A1 and CVD score, independent of age, sex, sexual maturation, race and weight status. There was a significant interaction effect of TV viewing $\times$ weight status $(P=0.002)$ on $W C$, and the negative influence of TV viewing on WC persisted in the overweight group $(P=0.031)$ but was attenuated in non-overweight adolescents $(P$ $>0.05$ ).
\end{abstract}

Conclusion: Excessive TV viewing seems to be related to an unfavorable CVD risk factors profile in adolescence. Reducing TV viewing in overweight adolescents might be beneficial to decrease abdominal body fat.

\section{Background}

Cardiovascular and metabolic diseases are the principal causes of mortality in developed countries [1]. Therefore, cardiovascular diseases (CVD) and metabolic risk factors are very important concerns in public health policies [2]. To prevent atherosclerosis, type 2 diabetes, and the metabolic syndrome, it is necessary to develop actions from childhood and adolescence because CVD risk factors track towards adulthood [3]. Likewise, the increasing prevalence of CVD risk factors in children and adoles-

* Correspondence: amarcos@if.csic.es

${ }^{1}$ Immunonutrition Research Group, Department of Metabolism and Nutrition, Instituto del Frio, Institute of Food Science, Technology and Nutrition (ICTAN), Spanish National Research Council (CSIC), Madrid, Spain

Full list of author information is available at the end of the article cents might be, at least in part, a response to the worldwide trends in pediatric overweight and obesity $[4,5]$.

Adequate habitual physical activity and a healthy diet are the basic cornerstones to prevent obesity and CVD [6]. However, chronic diseases result from the interaction among many factors [7], and the evaluation of other lifestyles could be relevant. In the last decades, the development of technologies has been related to sedentary behavior and obesity in children and adolescents [8]. Nowadays, there is a social trend to mistakenly consider physical activity and sedentary behaviors as opposite poles from the same continuous (e.g. if a child does not achieve enough physical activity, he or she may be categorized as sedentary or couch potato), but studies in adoles- 
cents have shown that time spent in sedentary behaviors must be considered independently of physical activity [9], and hence, both sedentary behavior and physical activity may have a different effect in the prevention and development of CVD.

Television (TV) viewing is a well-known sedentary behavior and too much time spent watching TV is considered an unhealthy behavior associated with obesity and other harmful health outcomes in youth [10]. Little is known about how TV viewing and CVD risk factors are linked in youth because the majority of the studies have been conducted in adults [11-14]. To our knowledge, in children and adolescents, several studies have analyzed the associations between TV viewing and individual CVD risk factors-abdominal fat $[15,16]$, lipid abnormalities $[17,18]$, hypertension $[19,20]$, insulin resistance [21]and only two studies have examined the associations using composite CVD risk scores [22,23]. The majority of the above mentioned studies did not show whether these associations were independent of body fat.

On the other hand, interventional studies reducing TV viewing in apparently healthy children and adolescents have shown small or no significant effects on obesity $[8,24]$, whereas interventions on obese children by decreasing time spent watching TV have shown a positive effect on obesity indicators $[25,26]$. Hence, these findings suggest that the effect of TV viewing on obesity might differ by weight status. Nevertheless, whether associations between TV viewing and CVD risks factors vary by weight status in adolescents have not been evaluated yet.

Therefore, the aim of the present study was to examine the independent association of excessive TV viewing with individual and clustered CVD risk factors in adolescents. Additionally, we also examined whether a different weight status modifies the associations between TV viewing and CVD risk factors.

\section{Methods}

\section{Design and participants}

The AVENA (Alimentación y Valoración del Estado Nutricional de los Adolescentes: Food and Assessment of the Nutritional Status of Spanish Adolescents) study is a cross-sectional and multicenter study performed in Spanish adolescents aged 13.0 to 18.5-years. Design and methodologies of the AVENA study have been previously described [27]. In brief, 2859 Spanish adolescents were assessed in 5 Spanish cities (Granada, Madrid, Murcia, Santander and Zaragoza) between 2000 and 2002. Health and lifestyle indicators, body composition, and healthrelated physical fitness were assessed in all adolescents. Moreover, in a subsample of 581 adolescents, blood samples were collected to determine hematological, lipid, immunological and genetic parameters. Of this subsample, a total of 214 boys and 211 girls ( $n=425,97 \%$ Caucasian) with complete and valid data on anthropometry measurements and self-reported time spent watching TV were included in the current study. Socioeconomic status (SES) was also parent-reported and defined by the educational achievement of the mother (elementary school, middle school, high school and university) but this information was available in 378 adolescents (89\%). Parents and guardians were informed about the characteristics and aims of the study, and they gave their written informed consent. The AVENA study protocol was approved by the Review Committee for Research Involving Human Subjects from Marques de Valdecilla University Hospital (Santander, Spain).

\section{Physical examination}

Height $(\mathrm{m})$ and body weight $(\mathrm{kg})$ were measured barefooted and wearing light underclothes. Height was measured to the nearest $1 \mathrm{~mm}$ and body weight to the nearest $0.05 \mathrm{~kg}$ by using a standard beam balance with a stadiometer. Body mass index (BMI) was calculated as body weight divided by height squared $\left(\mathrm{kg} / \mathrm{m}^{2}\right)$. Waist circumference $(\mathrm{WC})$ was measured $(\mathrm{cm})$ with a non-elastic tape to the nearest $1 \mathrm{~mm}$ between the lowest rib margin and the iliac crest, near the level of the umbilicus, at the end of gentle expiration. The anthropometric protocols in the AVENA study were previously harmonized and described elsewhere [28]. In the current study, overweight (including obesity) adolescents were classified according to ageand sex-specific cut offs proposed by the International Obesity Task Force [29]. At the time of the anthropometry measurements, sexual maturation of each adolescent was assessed (I to V) according to Tanner and Whitehouse [30]. The standard stages of sexual maturation describe breast and pubic hair development in adolescent girls, and genital and pubic hair development in adolescent boys.

\section{TV viewing}

Adolescents' time (hrs/day) watching TV was assessed by questionnaire. Adolescents were asked as follows: How many hours do you usually spend watching TV per day? Adolescents had to select one of the following categories: 1) None 2) Less than $1 / 2$ hour 3 ) Between $1 / 2-1$ hour 4 ) Between 1-3 hours 5) Between 3-4 hours 6) More than 4 hours. Similarly to previous studies in adolescents in the AVENA framework [31], those adolescents who spent $\leq 3$ hrs/day (categories 1 to 4 ) watching TV were considered as "low TV viewing", whereas adolescents who spent $>3$ hrs/day were classified as "high TV viewing" (categories 5 and 6). 


\section{Blood sampling}

After overnight fasting, blood samples were collected between 8:00 and 9:30 AM by venipuncture. Within 1-hr after blood collection, serum was separated by centrifugation and divided into aliquots. Triglycerides (TG), total cholesterol (TC), high-density lipoprotein cholesterol (HDL-C) and glucose were measured by enzymatic assay using a Hitachi 911 Analyzer (Roche Diagnostics, Indianapolis, Ind., USA). Low-density lipoprotein cholesterol (LDL-C) was calculated with the Friedewald formula: LDL-C = (TC-HDL-C) - (TG/5). Apolipoprotein (apo) AI, apo B-100 and lipoprotein(a) levels were measured using a immunonephelometric assay on Array 306 system (Beckman GMI, Inc., Albertville, MN, USA). Quality control of the assays was assured by the Regional Health Authority, as compulsory for all clinical laboratories in Spain. A more detailed description of the blood analysis has been reported elsewhere [32].

\section{Continuous CVD risk score}

A composite CVD risk score was created using TG, HDL$\mathrm{C}$, LDL-C, and glucose values. This CVD risk score including lipids and metabolic parameters has been used in a previous study with adolescents [33]. The four selected CVD factors were standardized by regressing them onto age, sex, sexual maturation and race variables. Once each CVD variable was regressed onto the independent variables, the standardized residual (Z-scores) was saved. Since the standardized HDL-C is inversely related to metabolic risk it was multiplied by -1 . The standardized residuals were summed to create the CVD risk score denoting the higher score the less favorable CVD profile.

\section{Statistical analysis}

The distribution of continuous variables was assessed for normality and natural-log transformations were performed when necessary. Data were described by mean \pm SD unless otherwise stated. Differences between adolescent boys and girls were determined by one-way analysis of variance (ANOVA) for continuous variables and the Chi-square test for categorical data.

Differences between non-overweight and overweight groups for individual CVD risk factors (WC, TG, TC, HDL-C, LDL-C, Apo A-1, Apo B-100, and lipoprotein(a)) were assessed by analysis of covariance (ANCOVA) adjusted by age, sex, sexual maturation and race. Differences between weight status groups for the continuous CVD risk score were assessed by ANOVA because the variable was previously age-, sex-, sexual maturation-and race-standardized.

Differences between TV viewing (low and high) groups for individuals CVD risk factors were assessed by ANCOVA adjusted by potential confounders whereas ANOVA was used for the continuous CVD risk score. To examine the independent associations between TV viewing and CVD risk factors, a second model was performed including weight status as a fixed factor. A final model was also performed including the interaction term TV viewing $\times$ weight status. The level of significance was set at $\mathrm{p}<0.05$ and analyses were carried out using SPSS (SPSS Inc., Chicago, IL, US) version 13.0 for Macintosh.

\section{Results}

Table 1 provides an overview of the characteristics of the study participants by sex. Adolescent boys were taller and heavier than girls but there was no significant difference in BMI levels. Sixty adolescent boys (28\%) and thirty-nine adolescent girls (19\%) were classified as overweight. For the CVD risk factors, adolescent boys had significantly higher abdominal body fat, and less favorable values of TG, HDL-C, glucose, and Apo A-1 than girls. In contrast, adolescent girls had less favorable values of TC, LDL-C and Apo B-100 than boys. Two hundred and twenty-five adolescents (53\%) were classified in the "high TV viewing" group and a significantly higher percentage of adolescent boys than girls were classified in the high TV viewing group $(\mathrm{p}=0.023)$.

Differences between weight status groups for CVD risk factors are shown in Table 2. Adolescents classified as overweight had less favorable values of WC, TG, HDL-C, LDL-C, Apo A-1, Apo B-100 than non-overweight adolescents controlling for age, sex, sexual maturation and race. Moreover, overweight adolescents also had a higher CVD risk score than non-overweight adolescents $(\mathrm{p}<$ 0.001).

Differences between TV viewing groups for CVD risk factors are shown in Table 3. Adolescents in the high TV viewing group had less favorable values of HDL-C, glucose and Apo A-1, controlling for potential confounders, as well as a lower CVD risk score $(\mathrm{p}<0.001)$. When weight status was also included into the model as a confounder variable (model 2), the main results did not change (Table 3).

Finally, we analyzed whether the influence of TV viewing on CVD risk factors differ by weight status including a TV viewing $\times$ weight status interaction term into the model (model 3). These analyses showed that differences between TV viewing groups for CVD risk factors remained significant, but there was a significant interaction effect of TV viewing $\times$ weight status on $\mathrm{WC}(\mathrm{p}=$ 0.002). Differences in WC across TV viewing and weight status groups in the adolescent sample are illustrated in Figure 1. Thus, the influence of TV viewing on WC in adolescents was only significant in the overweight group $(\mathrm{p}=0.031)$, whereas this influence was attenuated in the non-overweight group ( $\mathrm{p}>0.05)$. All the results did not change when analyses were adjusted for SES as a confounder variable (data not shown). 
Table 1: Baseline characteristics of the sample $(n=425)$

\begin{tabular}{|c|c|c|c|}
\hline & Adolescent boys $(n=214)$ & Adolescent girls $(n=211)$ & $\mathbf{p}$ \\
\hline Age (yrs) & $14.9 \pm 1.2$ & $14.8 \pm 1.4$ & 0.370 \\
\hline Weight (kg) & $64.4 \pm 13.3$ & $56.3 \pm 10.6$ & $<0.001$ \\
\hline Height (m) & $1.7 \pm 0.1$ & $1.6 \pm 0.1$ & $<0.001$ \\
\hline Body mass index $\left(\mathrm{kg} / \mathrm{m}^{2}\right)$ & $22.1 \pm 3.9$ & $21.6 \pm 3.5$ & 0.177 \\
\hline Non-overweight/Overweight & $154 / 60$ & $162 / 39$ & 0.020 \\
\hline Waist circumference $(\mathrm{cm})$ & $77.1 \pm 9.4$ & $71.1 \pm 8.4$ & $<0.001$ \\
\hline Sexual maturation (I/II/III/IV/V) & $1 / 10 / 28 / 86 / 89$ & $0 / 5 / 18 / 110 / 78$ & $<0.001$ \\
\hline Triglycerides $(\mathrm{mg} / \mathrm{dl})^{\S}$ & $71.1 \pm 31.8$ & $65.1 \pm 27.0$ & 0.037 \\
\hline Total cholesterol $(\mathrm{mg} / \mathrm{dl})^{\S}$ & $155.8 \pm 26.3$ & $170.1 \pm 25.4$ & $<0.001$ \\
\hline HDL-cholesterol $(\mathrm{mg} / \mathrm{dl})^{\S}$ & $51.4 \pm 10.0$ & $59.4 \pm 11.8$ & $<0.001$ \\
\hline LDL-cholesterol $(\mathrm{mg} / \mathrm{dl})^{\S}$ & $90.2 \pm 23.5$ & $97.8 \pm 22.7$ & 0.001 \\
\hline Glucose $(\mathrm{mg} / \mathrm{dl})^{\S}$ & $95.4 \pm 9.7$ & $91.5 \pm 8.4$ & $<0.001$ \\
\hline Apoliprotein-A1 (mg/dl)§ & $115.5 \pm 15.5$ & $125.5 \pm 17.5$ & $<0.001$ \\
\hline Apoliprotein-B100 (mg/dl)§ & $65.9 \pm 14.8$ & $69.3 \pm 13.4$ & 0.013 \\
\hline Lipoprotein(a) (mg/dl) $)^{\S}$ & $30.8 \pm 36.8$ & $31.6 \pm 38.9$ & 0.683 \\
\hline $\begin{array}{l}\text { Low TV viewing/High TV } \\
\text { viewing }{ }^{\dagger}\end{array}$ & $89 / 125$ & $111 / 100$ & 0.023 \\
\hline
\end{tabular}

Values are mean \pm SD. ${ }^{\S}$ Values were natural log-transformed, but not transformed values are presented in the table. ${ }^{\dagger}$ High TV viewing: $>3$ hrs/day. Statistical analyses were analysis of variance for continuous variables and the Chi-square test for categorical variables.

\section{Discussion}

The main results of our study suggest that excessive TV viewing is positively associated with CVD risk factors such as HDL-C, glucose, Apo A-1 and a continuous CVD risk score in adolescents, independently of potential confounders including weight status. These findings provide some evidence regarding the detrimental role of excessive TV viewing on CVD risk factors development in adolescence. In addition, further analyses revealed that weight status might modify the influence of TV viewing on abdominal body fat. Thus, the negative influence of TV viewing on WC remained in the overweight group but was attenuated in the non-overweight group.

Several studies in adults have shown similar findings to those found in the current study. In these studies the time spent watching TV has been positively associated with CVD risk factors [11-14]. For example, Healy et al. [17] showed a detrimental dose-response association of TV

Table 2: Differences in cardiovascular disease (CVD) risk factors between weight status groups among adolescents $(n=425)$

\begin{tabular}{|c|c|c|c|}
\hline & Non-overweight $(n=326)$ & Overweight $^{\dagger}(n=99)$ & $\mathbf{p}$ \\
\hline Waist circumference $(\mathrm{cm})^{\ddagger}$ & $72.0 \pm 2.1$ & $86.5 \pm 2.2$ & $<0.001$ \\
\hline Triglycerides $(\mathrm{mg} / \mathrm{dl})^{\neq \S}$ & $63.0 \pm 9.4$ & $71.7 \pm 9.9$ & 0.011 \\
\hline Total cholesterol $(\mathrm{mg} / \mathrm{dl})^{\ddagger \S}$ & $167.1 \pm 8.2$ & $169.3 \pm 8.7$ & 0.462 \\
\hline HDL-cholesterol $(\mathrm{mg} / \mathrm{dl})^{\neq \S}$ & $61.5 \pm 3.3$ & $55.7 \pm 3.6$ & $<0.001$ \\
\hline LDL-cholesterol $(\mathrm{mg} / \mathrm{dl})^{\neq \S}$ & $93.0 \pm 7.2$ & $99.3 \pm 7.8$ & 0.019 \\
\hline Glucose $(\mathrm{mg} / \mathrm{dl})^{\ddagger \S}$ & $91.9 \pm 2.8$ & $93.6 \pm 3.0$ & 0.109 \\
\hline Apoliprotein-A1 (mg/dl)キ§ & $124.0 \pm 5.0$ & $119.1 \pm 5.5$ & 0.003 \\
\hline Apoliprotein-B100 (mg/dl) $)^{\ddagger \S}$ & $65.7 \pm 4.5$ & $69.5 \pm 4.7$ & 0.021 \\
\hline Lipoprotein (a) $(\mathrm{mg} / \mathrm{dl})^{\neq \S}$ & $30.1 \pm 2.0$ & $34.8 \pm 4.3$ & 0.437 \\
\hline CVD risk score ${ }^{\#}$ & $-0.9 \pm 0.7$ & $0.4 \pm 0.7$ & $<0.001$ \\
\hline
\end{tabular}

Values are mean $\pm \mathrm{SE} .{ }^{\dagger}$ Including obesity. ${ }^{\ddagger}$ Analysis of covariance adjusted by age, sex, sexual maturation and race. ${ }^{\S}$ Values were natural logtransformed, but not transformed values are presented in the table. \# Analysis of variance. 
Table 3: Differences in cardiovascular disease (CVD) risk factors between TV viewing groups ${ }^{\dagger}$ among adolescents $(n=425)$

\begin{tabular}{|c|c|c|c|c|}
\hline & & Low TV viewing $(n=200)$ & High TV viewing $(n=225)$ & $\mathbf{p}$ \\
\hline \multirow[t]{2}{*}{ Waist circumference $(\mathrm{cm})$} & Model 1 & $72.2 \pm 2.9$ & $73.2 \pm 2.9$ & 0.259 \\
\hline & Model 2 & $78.8 \pm 2.1$ & $79.5 \pm 2.1$ & 0.299 \\
\hline \multirow[t]{2}{*}{ Triglycerides $(\mathrm{mg} / \mathrm{dl})^{\S}$} & Model 1 & $60.3 \pm 9.6$ & $65.3 \pm 9.4$ & 0.085 \\
\hline & Model 2 & $64.1 \pm 9.7$ & $69.0 \pm 9.5$ & 0.096 \\
\hline \multirow[t]{2}{*}{ Total cholesterol $(\mathrm{mg} / \mathrm{dl})^{\S}$} & Model 1 & $166.8 \pm 8.4$ & $167.5 \pm 8.3$ & 0.809 \\
\hline & Model 2 & $167.8 \pm 8.6$ & $168.4 \pm 8.4$ & 0.824 \\
\hline \multirow[t]{2}{*}{ HDL-cholesterol $(\mathrm{mg} / \mathrm{dl})^{\S}$} & Model 1 & $63.2 \pm 3.5$ & $60.1 \pm 3.4$ & 0.004 \\
\hline & Model 2 & $60.6 \pm 3.5$ & $57.6 \pm 3.4$ & 0.005 \\
\hline \multirow[t]{2}{*}{ LDL-cholesterol $(\mathrm{mg} / \mathrm{dl})^{\S}$} & Model 1 & $91.6 \pm 7.5$ & $94.3 \pm 7.4$ & 0.242 \\
\hline & Model 2 & $94.4 \pm 7.6$ & $97.0 \pm 7.5$ & 0.265 \\
\hline \multirow[t]{2}{*}{ Glucose $(\mathrm{mg} / \mathrm{dl})^{\S}$} & Model 1 & $89.7 \pm 2.8$ & $93.2 \pm 2.8$ & $<0.001$ \\
\hline & Model 2 & $90.4 \pm 2.9$ & $93.9 \pm 2.8$ & $<0.001$ \\
\hline \multirow[t]{2}{*}{ Apoliprotein-A1 (mg/dl)§ } & Model 1 & $127.7 \pm 5.3$ & $122.7 \pm 5.2$ & 0.002 \\
\hline & Model 2 & $125.2 \pm 5.3$ & $120.4 \pm 5.2$ & 0.002 \\
\hline \multirow[t]{2}{*}{ Apoliprotein-B100 $(\mathrm{mg} / \mathrm{dl})^{\S}$} & Model 1 & $65.0 \pm 4.6$ & $66.4 \pm 4.5$ & 0.337 \\
\hline & Model 2 & $66.7 \pm 4.6$ & $68.0 \pm 4.6$ & 0.366 \\
\hline \multirow[t]{2}{*}{ Lipoprotein(a) (mg/dl)§ } & Model 1 & $26.5 \pm 12.3$ & $27.1 \pm 12.2$ & 0.876 \\
\hline & Model 2 & $28.9 \pm 12.5$ & $29.3 \pm 12.4$ & 0.900 \\
\hline \multirow[t]{2}{*}{ CVD risk score ${ }^{\ddagger}$} & Model 1 & $-1.5 \pm 0.7$ & $-0.5 \pm 0.7$ & $<0.001$ \\
\hline & Model 2 & $-0.9 \pm 0.7$ & $0.0 \pm 0.7$ & $<0.001$ \\
\hline
\end{tabular}

Values are mean $\pm \mathrm{SE}$. ${ }^{+}$High TV viewing: $>3$ hrs/day.

Model 1: Analysis of covariance adjusted by age, sex, sexual maturation and race. Model 2: Analysis of covariance adjusted by model $1+$ weight status. ${ }^{\S}$ Values were natural log-transformed, but not transformed values are presented in the table. ${ }^{\ddagger}$ Analysis of variance in Model 1 and analysis of variance adjusted by weight status in Model 2 .

viewing with WC, systolic blood pressure and 2-h plasma glucose in 4064 Australian adults [17]. Recently, Dustan et al. [34] have shown that excessive TV viewing is associated with increased risk of all-cause and CVD mortality in 8800 Australian adults. Similar results were found in a men sample where the combination of time riding in a car and time spent watching TV were positively associated with CVD death [35].

Despite of these findings in adult populations, the evidence linking TV viewing to CVD risk factors in children and adolescents is limited. For example, positive associations between TV viewing and abdominal body fat have been found in cross-sectional studies $[15,16]$. Nevertheless, several reviews have stated the weakness of these findings because poor results have been found in longitudinal and interventional studies [8]. Significant associations between TV viewing and blood markers (TC, insulin and glucose) $[17,18]$ and blood pressure have also been found in children and adolescents [19,20]. However, only in some cases body fat indicators were included as a 


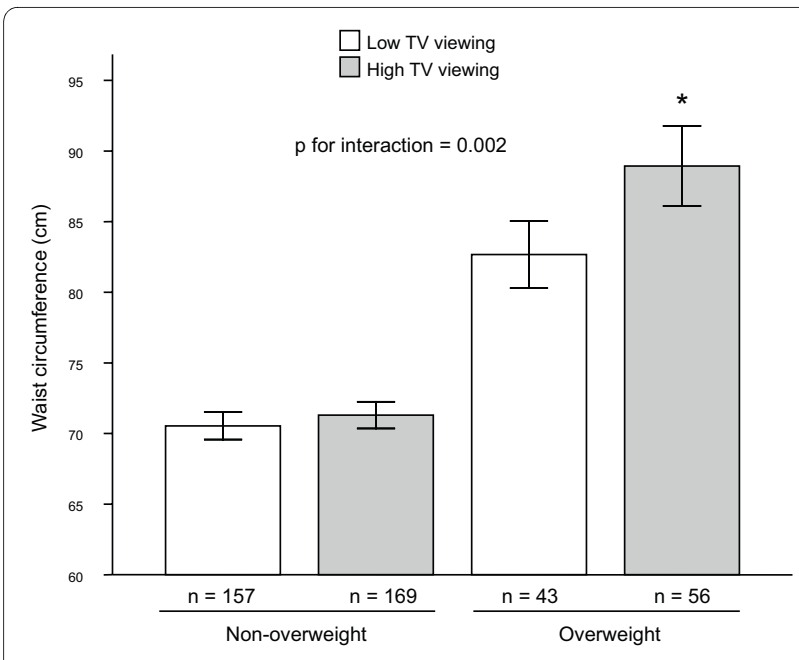

Figure 1 Differences in waist circumference across weight status and TV viewing groups among adolescents $(n=425)$. Values are mean \pm SE. High TV viewing: $>3$ hrs/day. Analyses of covariance adjusted by age, sex, sexual maturation and race. ${ }^{*} p=0.031$ compared with the overweight/low TV viewing group.

confounder variable into analyses. For this reason, we cannot know whether the influence of TV viewing on CVD risk factors is independent of body fat-direct roleor whether body fat plays a pivotal role between TV viewing and a less favorable CVD risk factor profile-indirect role.

In the European Youth Heart Study, Ekelund et al. [22] reported an independent association between TV viewing and metabolic syndrome risk factors in 1921 children and adolescents from 3 regions in Europe (Denmark, Estonia, and Portugal), but this association was mediated by adiposity (sum of 4 skinfold-thicknesses). Hence, the authors concluded the importance of reducing the time spent watching TV among children and adolescents in order to reduce directly body fat, and indirectly CVD risk factors. On the contrary, the associations between TV viewing and several CVD risk factors in the current study were not mediated by weight status. Interestingly, we also found that the influence of TV viewing on WC varied by weight status. The detrimental influence of TV viewing was maintained in the overweight group but not in the non-overweight group. These results suggest that reducing $\mathrm{TV}$ viewing time in overweight adolescents may have a beneficial influence on abdominal body fat. This interesting finding might explain the mixed effects found in intervention studies that decrease sedentary behaviors in apparently healthy and overweight children and adolescent $[8,24-26]$.

TV viewing is commonly used as a proxy to describe sedentary behavior even though the capacity to describe sedentary time using this approach is constantly questioned [36,37]. New research directions have used objective methods to assess daytime sedentary patterns and several reports have suggested the use of accelerometry for these purposes [38]. Assessments using objective measures follow the idea of "inactivity physiology" posited by Hamilton et al. [39]. In order to observe the differences between both methods, we have previously assessed sedentariness using sedentary time by accelerometry, and TV viewing and computer use by parentreport in a 3- to 8-year-old sample [20]. On average, children spent $5 \mathrm{hrs} /$ day in sedentary time and $1.5 \mathrm{hrs} /$ day in screen time (TV + computer). These results show large differences between both methods. We consider that sedentary behavior with or without technology-mainly sitting time- and sedentary behavior using new technologies -mainly TV viewing- must be considered independently each other because both may be important in the development and prevention of CVD.

$\mathrm{TV}$ viewing in children and adolescents is usually associated with unhealthy behaviors. Firstly, TV viewing is associated with high consumption of soft drinks, salt, snacks, fat and low fruit and vegetable consumption [40]. Secondly, TV viewing may contribute to the development of sleep problems from adolescence to adulthood [41]. Thirdly, TV viewing may restrict the possibility of youth to participate in physical activity [42]. Fourthly, TV viewing contributes to inactive physiology as mentioned above. Hence, when reduction of time watching TV is suggested to prevent obesity and CVD risk factors, we may have influence on diet, sleep, physical activity and physical inactivity patterns that occur concurrently with TV viewing. Therefore, it is necessary to develop actions to reduce time watching TV from an early age. For children and adolescents, the American Academy of Pediatric recommends limits to no more than 2 hours per day of sedentary technologies, especially TV viewing [10]. Similarly, the Healthy People 2010 initiative promoted by the U.S. Department of Health and Human Services included the following objective: "to increase the proportion of adolescents who view television 2 or fewer hours on a school day" http://www.healthypeople.gov. As other authors [43,44], we could not use the 2 hours per day cut-off point. In our study, more than $50 \%$ adolescents spent $>3$ hrs/day watching $\mathrm{TV}$, which is a similar prevalence to that found in a previous study in adolescents [44].

Results found in our study confirm that an overweight status is positively associated with individual (WC, TG, HDL-C, LDL-C, apo A-1, apo B-100) and clustered CVD risk factors in adolescents. Therefore, a special focus of attention must be aimed at overweight adolescents who view too much TV. Moreover, future studies are encouraged to evaluate more health indicators in addition to obesity outcomes (e.g. BMI, \% body fat, WC) because the evidence is scarce with other CVD risk factors. For example, in addition to the traditional CVD risk factors related to the metabolic syndrome, we have analyzed the associa- 
tions of TV viewing with Apo A-1, Apo B-100, and lipoprotein(a). Thus, our results suggest that Apo A-1 is inversely and independently associated with TV viewing. Recently, childhood and adolescence Apo A-1 levels have been considered predictors of subclinical atherosclerosis in adulthood [45].

Several limitations must be also mentioned in the current study. Our results are limited due to its cross-sectional design and causal directionality cannot be inferred. Moreover, one blood sample was used and that might not accurately reproduce long-term lipid and metabolic abnormalities. Unfortunately, blood pressure was not available in the AVENA Study, and therefore, we cannot compare findings from previous studies. TV viewing was measured using a single-response item. This type of questions to assess TV viewing has been widely used in large sample studies because objective measurements (direct observation, video, TV time manager) are not usually feasible in population studies. In children and adolescents, an adequate reliability and acceptable validity of these single 1-item questions to assess TV viewing have been observed [46]. In spite of this, single-response questions are preferred rather than combined questions (e.g. How many hours do you usually spend watching TV and using computer per day?) because computer use and video game play may have a different effect on metabolic and physiologic parameters [47]. Finally, we did not assess dietary patterns during TV viewing. Ekelund et al. [22] found that associations between TV viewing and CVD risk factors and adiposity were attenuated when dietary behavior while viewing TV was controlled into the model although results were not shown.

\section{Conclusions}

Excessive TV viewing might aggravate several CVD risk factors in adolescents independently of their weight status. Furthermore, reducing the time spent watching TV might improve abdominal body fat in overweight adolescents. Specific intervention strategies are necessary in overweight adolescents who spent too much time daily watching TV. Experimental studies examining the role of $\mathrm{TV}$ viewing on traditional and new CVD risk factors in children and adolescents are warranted.

\section{Competing interests}

The authors declare that they have no competing interests.

\section{Authors' contributions}

Statistical analysis: DMG; Draft the manuscript: DMG; Funding and overall concept and design: AM, LAM, MGF and MD. Interpretation and acquisition of data: DMG, JPRL, PC, SGM, GVR, MMM, MGF, MD, LAM, OLV, JCE and AM. All authors read and approved the final manuscript.

\section{Acknowledgements}

The authors express their sincere gratitude to the adolescents who participated in this study. The AVENA Study was supported by the Spanish Ministry of Health, FIS (00/0015) and grants from Panrico S.A., Madaus S.A. and Procter \& Gamble S.A. DMG was supported by a grant from the Spanish Ministry of Edu- cation and Science (AP2006-02464). JPRL, GVR, MGF and LAM were also supported by a grant from the Spanish Ministry of Health: Maternal, Child Health and Development Network (number RD08/0072).

AVENA Study Group:

Coordinator: A Marcos, Madrid. Local coordinators: MJ Castillo, Granada; A Marcos, Madrid; S Zamora, Murcia; M García Fuentes, Santander; M Bueno, Zaragoza. Granada: MJ Castillo, MD Cano, R Sola (Biochemistry); A Gutiérrez, JL Mesa, JR Ruiz (Physical fitness); M Delgado, P Tercedor, P Chillón (Physical activity), M Martín-Matillas, F Carreño, FB Ortega, GV Rodríguez, R Castillo, F Arellano (Collaborators). Universidad de Granada. E-18071 Granada. Madrid: A Marcos, M González-Gross, J Wärnberg, S Medina, F Sánchez-Múniz, E Nova, A Montero, B de la Rosa, S Gómez, S Samartín, J Romeo, R Álvarez, (Coordination, immunology) A Álvarez (Cytometric analysis) L Barrios (Statistical analysis) A Leyva, B Payá (Psychological assessment). L Martínez, E Ramos, R Ortiz, A Urzanqui. (Collaborators). Instituto de Nutrición y Bromatología. Consejo Superior de Investigaciones Científicas (CSIC). E-28040 Madrid. Murcia: S Zamora, M Garaulet, F Pérez-Llamas, JC Baraza, JF Marín, F Pérez de Heredia, MA Fernández, C González, R García, C Torralba, E Donat, E Morales, MD García, JA Martínez, JJ Hernández, A Asensio, FJ Plaza, MJ López (Diet analysis). Dpto. Fisiología. Universidad de Murcia. E-30100 Murcia. Santander: M García Fuentes, D GonzálezLamuño, P de Rufino, C Redondo-Figuero, MJ Noriega, R Lanza-Saiz, T Amigo (Genetic study). Dpto. Pediatría. Universidad de Cantabria. E - 19003 Santander. Zaragoza: M Bueno, LA Moreno, A Sarriá, J Fleta, G Rodríguez, CM Gil, MI Mesana, JA Casajús, Vicente Blay, María Guadalupe Blay. (Anthropometric assessment). Escuela Universitaria de Ciencias de la Salud. Universidad de Zaragoza. E-50009 Zaragoza.

\section{Author Details}

${ }^{1}$ Immunonutrition Research Group, Department of Metabolism and Nutrition, Instituto del Frio, Institute of Food Science, Technology and Nutrition (ICTAN), Spanish National Research Council (CSIC), Madrid, Spain, 2Department of Physical Education, Sport and Human Movement, Universidad Autónoma de Madrid, Madrid, Spain, ${ }^{3}$ School of Health Sciences, University of Zaragoza, Zaragoza, Spain, ${ }^{4}$ Department of Physical Education and Sport, School of Physical Activity and Sport Sciences, University of Granada, Granada, Spain, ${ }^{5}$ Department of Pediatrics, University of Cantabria, Santander, Spain and ${ }^{6}$ Department of Kinesiology and Pediatrics \& Human Development, East Lansing, MI, USA

Received: 2 December 2009 Accepted: 25 May 2010

Published: 25 May 2010

\section{References}

1. Lloyd-Jones D, Adams R, Carnethon M, De Simone G, Ferguson TB, Flegal K, Ford E, Furie K, Go A, Greenlund K, Haase N, Hailpern S, Ho M, Howard V, Kissela B, Kittner S, Lackland D, Lisabeth L, Marelli A, McDermott M, Meigs J, Mozaffarian D, Nichol G, O'Donnell C, Roger V, Rosamond W, Sacco R, Sorlie P, Stafford R, Steinberger J, Thom T, Wasserthiel-Smoller S, Wong N, Wylie-Rosett J, Hong Y, American Heart Association Statistics Committee and Stroke Statistics Subcommittee: Heart disease and stroke statistics-2009 update: a report from the American Heart Association Statistics Committee and Stroke Statistics Subcommittee. Circulation 2009, 119:e21-181.

2. Beaglehole R, Ebrahim S, Reddy S, Voûte J, Leeder S, Chronic Disease Action Group: Prevention of chronic diseases: a call to action. Lancet 2007, 370:2152-2157.

3. Eisenmann JC, Welk GJ, Wickel EE, Blair SN, Aerobics Center Longitudina Study: Stability of variables associated with the metabolic syndrome from adolescence to adulthood: the Aerobics Center Longitudinal Study. Am J Hum Biol 2004, 16:690-696.

4. Wang $Y$, Lobstein T: Worldwide trends in childhood overweight and obesity. Int J Pediatr Obes 2006, 1:11-25.

5. Bibbins-Domingo K, Coxson P, Pletcher MJ, Lightwood J, Goldman L: Adolescent overweight and future adult coronary heart disease. NEngl J Med 2007, 357:2371-2379.

6. World Health Organization: Global Strategy on Diet Physical Activity and Health. Geneva: WHO; 2004.

7. Lobstein T, Baur L, Uauy R, IASO International Obesity TaskForce: Obesity in children and young people: a crisis in public health. Obes Rev 2004, 5(Suppl 1):S4-104 
8. Rey-López JP, Vicente-Rodríguez G, Biosca M, Moreno LA: Sedentary behaviour and obesity development in children and adolescents. Nutr Metab Cardiovasc Dis 2008, 18:242-251

9. Taveras EM, Field AE, Berkey CS, Rifas-Shiman SL, Frazier AL, Colditz GA, Gillman MW: Longitudinal relationship between television viewing and leisure-time physical activity during adolescence. Pediatrics 2007, 119:e314-319.

10. American Academy of Pediatrics. Committee on Public Education: Children, adolescents, and television. Pediatrics 2001, 107:423-426.

11. Aadahl M, Kjaer M, Jørgensen T: Influence of time spent on TV viewing and vigorous intensity physical activity on cardiovascular biomarkers. The Inter 99 study. Eur J Cardiovasc Prev Rehabil 2007, 14:660-665.

12. Dunstan DW, Salmon J, Owen N, Armstrong T, Zimmet PZ, Welborn TA, Cameron AJ, Dwyer T, Jolley D, Shaw JE, AusDiab Steering Committee: Associations of TV viewing and physical activity with the metabolic syndrome in Australian adults. Diabetologia 2005, 48:2254-2261.

13. Jakes RW, Day NE, Khaw KT, Luben R, Oakes S, Welch A, Bingham S, Wareham NJ: Television viewing and low participation in vigorous recreation are independently associated with obesity and markers of cardiovascular disease risk: EPIC-Norfolk population-based study. Eur J Clin Nutr 2003, 57:1089-1096.

14. Healy GN, Dunstan DW, Salmon J, Shaw JE, Zimmet PZ, Owen N: Television time and continuous metabolic risk in physically active adults. Med Sci Sports Exerc 2008, 40:639-645.

15. Ortega FB, Ruiz JR, Sjöström M: Physical activity, overweight and central adiposity in Swedish children and adolescents: the European Youth Heart Study. Int J Behav Nutr Phys Act 2007, 4:61.

16. Ortega FB, Tresaco B, Ruiz JR, Moreno LA, Martin-Matillas M, Mesa JL, Warnberg J, Bueno M, Tercedor P, Gutiérrez A, Castillo MJ, AVENA Study Group: Cardiorespiratory fitness and sedentary activities are associated with adiposity in adolescents. Obesity (Silver Spring) 2007, 15:1589-1599.

17. Wong ND, Hei TK, Qaqundah PY, Davidson DM, Bassin SL, Gold KV: Television viewing and pediatric hypercholesterolemia. Pediatrics 1992, 90:75-79.

18. Guillaume M, Lapidus L, Björntorp P, Lambert A: Physical activity, obesity, and cardiovascular risk factors in children. The Belgian Luxembourg Child Study II. Obes Res 1997, 5:549-556.

19. Pardee PE, Norman GJ, Lustig RH, Preud'homme D, Schwimmer JB: Television viewing and hypertension in obese children. Am J Prev Med 2007, 33:439-443.

20. Martinez-Gomez D, Tucker J, Heelan KA, Welk GJ, Eisenmann JC: Associations between sedentary behavior and blood pressure in young children. Arch Pediatr Adolesc Med 2009, 163:724-730.

21. Margeirsdottir HD, Larsen JR, Brunborg C, Sandvik L, Dahl-Jørgensen K, Norwegian Study Group for Childhood Diabetes: Strong association between time watching television and blood glucose control in children and adolescents with type 1 diabetes. Diabetes Care 2007, 30:1567-1570

22. Ekelund U, Brage S, Froberg K, Harro M, Anderssen SA, Sardinha LB, Riddoch C, Andersen LB: TV viewing and physical activity are independently associated with metabolic risk in children: the European Youth Heart Study. PLoS Med 2006, 3:e488.

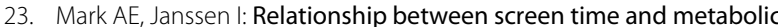
syndrome in adolescents. J Public Health (Oxf) 2008, 30:153-160.

24. Robinson TN: Reducing children's television viewing to prevent obesity: a randomized controlled trial. JAMA 1999, 282:1561-1567.

25. Epstein LH, Paluch RA, Gordy CC, Dorn J: Decreasing sedentary behaviors in treating pediatric obesity. Arch Pediatr Adolesc Med 2000, 154:220-226.

26. Faith MS, Berman N, Heo M, Pietrobelli A, Gallagher D, Epstein LH, Eiden MT, Allison DB: Effects of contingent television on physical activity and television viewing in obese children. Pediatrics 2001, 107:1043-1048.

27. González-Gross M, Castillo MJ, Moreno L, Nova E, González-Lamuño D, Pérez-Llamas F, Gutiérrez A, Garaulet M, Joyanes M, Leiva A, Marcos A: [Feeding and assessment of nutritional status of spanish adolescents (AVENA study). Evaluation of risks and interventional proposal. I. Methodology]. Nutr Hosp 2003, 18:15-28.

28. Moreno LA, Joyanes M, Mesana MI, González-Gross M, Gil CM, Sarría A, Gutierrez A, Garaulet M, Perez-Prieto R, Bueno M, Marcos A, AVENA Study Group: Harmonization of anthropometric measurements for a multicenter nutrition survey in Spanish adolescents. Nutrition 2003, 19:481-486
29. Cole TJ, Bellizzi MC, Flegal KM, Dietz WH: Establishing a standard definition for child overweight and obesity worldwide: international survey. BMJ 2000, 320:1240-1243.

30. Tanner JM, Whitehouse RH: Clinical longitudinal standards for height, weight, height velocity, weight velocity, and stages of puberty. Arch Dis Child 1976, 51:170-179.

31. Vicente-Rodríguez G, Ortega FB, Rey-López JP, España-Romero V, Blay VA, Blay G, Martín-Matillas M, Moreno LA, AVENA-Zaragoza group: Extracurricular physical activity participation modifies the association between high TV watching and low bone mass. Bone 2009, 45:925-930.

32. Ruiz JR, Ortega FB, Moreno LA, Wärnberg J, Gonzalez-Gross M, Cano MD, Gutierrez A, Castillo MJ, AVENA Study Group: Reference values for serum lipids and lipoproteins in Spanish adolescents: the AVENA study. Soz Praventivmed 2006, 51:99-109.

33. Mesa JL, Ruiz JR, Ortega FB, Wärnberg J, González-Lamuño D, Moreno LA, Gutiérrez A, Castillo MJ: Aerobic physical fitness in relation to blood lipids and fasting glycaemia in adolescents: influence of weight status. Nutr Metab Cardiovasc Dis 2006, 16:285-293.

34. Dunstan DW, Barr EL, Healy GN, Salmon J, Shaw JE, Balkau B, Magliano DJ, Cameron AJ, Zimmet PZ, Owen N: Television viewing time and mortality: the Australian Diabetes, Obesity and Lifestyle Study (AusDiab). Circulation 2010, 121:384-391.

35. Warren TY, Barry V, Hooker SP, Sui X, Church TS, Blair SN: Sedentary Behaviors Increase Risk of Cardiovascular Disease Mortality in Men. Med Sci Sports Exerc 2009 in press

36. Bryant MJ, Lucove JC, Evenson KR, Marshall S: Measurement of television viewing in children and adolescents: a systematic review. Obes Rev 2007, 8:197-209.

37. Sugiyama T, Healy GN, Dunstan DW, Salmon J, Owen N: Is television viewing time a marker of a broader pattern of sedentary behavior? Ann Behav Med 2008, 35:245-250.

38. Pate RR, O'Neill JR, Lobelo F: The evolving definition of "sedentary". Exerc Sport Sci Rev 2008, 36:173-178.

39. Hamilton MT, Hamilton DG, Zderic TW: Role of low energy expenditure and sitting in obesity, metabolic syndrome, type 2 diabetes, and cardiovascular disease. Diabetes 2007, 56:2655-2667.

40. Matheson DM, Killen JD, Wang Y, Varady A, Robinson TN: Children's food consumption during television viewing. Am J Clin Nutr 2004, 79:1088-1094

41. Johnson JG, Cohen P, Kasen S, First MB, Brook JS: Association between television viewing and sleep problems during adolescence and early adulthood. Arch Pediatr Adolesc Med 2004, 158:562-568.

42. Epstein LH, Roemmich JN: Reducing sedentary behavior: role in modifying physical activity. Exerc Sport Sci Rev 2001, 29:103-108.

43. Eisenmann JC, Bartee RT, Smith DT, Welk GJ, Fu Q: Combined influence of physical activity and television viewing on the risk of overweight in US youth. Int J Obes (Lond) 2008, 32:613-618.

44. Pate RR, Wang CY, Dowda M, Farrell SW, O'Neill JR: Cardiorespiratory fitness levels among US youth 12 to 19 years of age: findings from the 1999-2002 National Health and Nutrition Examination Survey. Arch Pediatr Adolesc Med 2006, 160:1005-1012.

45. Juonala M, Viikari JS, Kähönen M, Solakivi T, Helenius H, Jula A, Marniemi J, Taittonen L, Laitinen T, Nikkari T, Raitakari OT: Childhood levels of serum apolipoproteins B and A-I predict carotid intima-media thickness and brachial endothelial function in adulthood: the cardiovascular risk in young Finns study. J Am Coll Cardiol 2008, 52:293-299.

46. Schmitz KH, Harnack L, Fulton JE, Jacobs DR Jr, Gao S, Lytle LA, Van Coevering P: Reliability and validity of a brief questionnaire to assess television viewing and computer use by middle school children. J Sch Health 2004, 74:370-377.

47. Wang $X$, Perry AC: Metabolic and physiologic responses to video game play in 7- to 10-year-old boys. Arch Pediatr Adolesc Med 2006, 160:411-415.

\section{Pre-publication history}

The pre-publication history for this paper can be accessed here: http://www.biomedcentral.com/1471-2458/10/274/prepub

doi: $10.1186 / 1471-2458-10-274$

Cite this article as: Martinez-Gomez et al., Excessive TV viewing and cardiovascular disease risk factors in adolescents. The AVENA cross-sectional study BMC Public Health 2010, 10:274 